\title{
Clinical Results for Bladder Cancer Treated by Radiotherapy Without Concurrent Standard Chemotherapy
}

\author{
MASAKUNI SAKAGUCHI ${ }^{1}$, TOSHIYA MAEBAYASHI ${ }^{1}$, TAKUYA AIZAWA ${ }^{1}$, \\ NAOYA ISHIBASHI ${ }^{1}$ and TSUTOMU SAITO ${ }^{2}$ \\ ${ }^{1}$ Department of Radiology, Nihon University School of Medicine, Tokyo, Japan; \\ ${ }^{2}$ Sonodakai Radiation Oncology Clinic, Tokyo, Japan
}

\begin{abstract}
Aim: To evaluate clinical outcomes of threedimensional conformal radiotherapy (3D-CRT) alone in patients with bladder cancer who were unfit for concurrent standard chemotherapy. Patients and Methods: Between January 2007 and May 2016, 34 patients (20 men, 14 women) aged 65-97 years (median $=83$ ) with bladder cancer cT1-4bN0-1M1 were treated with conformal whole-bladder radiotherapy with fractions of 1.8-3 Gy up to a total dose of 40-50 Gy. Results: Median survival was 10 months (range =1-99); 1-year and 3-year survival was $51.4 \%$ and $34.3 \%$, respectively. Radiation dose $>50$ Gy was associated with improved survival. Three-year local control $(L C)$ rate was $58.8 \%$. On multivariate analysis, only radiation dose showed a significant association with LC. Conclusion: Our results demonstrated the safety and feasibility of radiotherapy in patients with bladder cancer unfit for concurrent standard chemotherapy. A higher radiation dose may confer superior LC and overall survival (OS) without complications.
\end{abstract}

The annual incidence of bladder cancer in Japan has increased in recent years to approximately 7.6 per 100,000 people (1). Up to $45 \%$ of all newly diagnosed bladder cancers are pathologically high-grade, more than half of which are muscle-invasive at the time of diagnosis (2). Muscle-invasive bladder cancer (MIBC) has a dismal prognosis with 5-year survival rates of 30-50\% depending on the type of treatment (3-6). The standard therapy for MIBC

Correspondence to: Masakuni Sakaguchi, Department of Radiology, Nihon University School of Medicine, 30-1, Oyaguchi Kami-cho, Itabashi-ku, Tokyo, 173-8610, Japan. Tel: +81 339728111 (Ext. 2554), Fax: +81339582454, e-mail: sakaguchi.masakuni@nihonu.ac.jp

Key Words: Concurrent chemoradiotherapy, bladder cancer, threedimensional conformal radiotherapy, whole-bladder radiotherapy. is radical cystectomy (7), which is associated with 3-year recurrence-free survival rates of about $60 \%(4,8-10)$.

Trimodality treatments that combine radiochemotherapy based on cisplatin (CDDP) with transurethral resection of the bladder tumour (TUR-BT) are usually only offered to patients with intent to preserve bladder or in whom surgery is contraindicated due to current disease and/or advanced age (11-13). However, the optimal sequence of approach for MIBC is not clear (14). Although a slightly favourable survival is seen in patients who are treated with an optimal bladder conserving multimodality approach (surgery plus radiotherapy or concurrent chemoradiation therapy), the superiority of surgery over a bladder-preserving strategy has not been proven $(7,15-18)$.

Concurrent chemoradiotherapy (CCRT), a standard approach for bladder preservation with radical or palliative intent (19-21), is preferred in patients who are not suitable candidates for radical cystectomy owing to poor general condition, comorbidity or extension of the disease. CCRT has been shown to confer superior locoregional control (LC) and overall survival (OS) compared to that with radiotherapy alone $(5,11,22)$. However, chemotherapy is sometimes not administered because of potential adverse effects, poor renal function due to hydronephrosis, poor associated quality of life (QOL) or on patient's refusal. This leaves the combination of TUR-BT and radiotherapy alone as the only treatment option to control tumour and haematuria.

The use of radiotherapy in very elderly patients provides an opportunity to treat these patients. The reported incidence of acute (grade $\mathrm{G} \geq 2$ ) and late toxicity associated with radiation dose of 55-70 Gy to the bladder is $20-67 \%$ and 7$17 \%$, respectively (23-28). These figures may not be extrapolated to patients with bladder cancer who are unable to receive chemotherapy due to advanced age and/or associated morbidity. Data on outcomes achieved with use of radiotherapy alone in elderly patients with bladder cancer and/or those with significant comorbidity, are rather limited. In this study, we evaluated clinical outcomes and toxicity of 
conformal radiotherapy alone in elderly patients with bladder cancer who were unfit for concurrent standard chemotherapy.

\section{Patients and Methods}

This retrospective study included 34 patients (20 males) aged 6597 years (median $=83$ ) with histological or cytological diagnosis of bladder cancer who received three-dimensional conformal radiotherapy (3D-CRT), without standard chemotherapy (CDDPbased) between January 2007 and May 2016. At our Institute, the routine treatment protocol for MIBC is either radical cystectomy and/or preoperative chemotherapy. Patients with poor general condition, old age and those who do not consent to radical cystectomy are treated with CCRT-based cisplatin protocol.

Standard chemotherapy (MVAC: methotrexate, vinblastine, doxorubicin, cisplatin, GC: gemcitabine, cisplatin) for MIBC was indicated in patients with a performance status (PS) of 0-1 and renal function within the normal limit. Although there was no strict agelimit, a cut-off of 85 years was used as the upper age limit for patients with PS 2. Even in patients who met the indications for standard chemotherapy, 3D-CRT alone was selected for patients who refused chemotherapy.

The most common reasons for selecting radiotherapy alone were renal impairment, followed by poor PS, increased age and patient refusal. Repeat TUR-BT was performed as the standard treatment for non-muscle-invasive bladder cancer (T1); radiotherapy treatment was not considered until the disease was difficult to treat with further TUR-BT or could not be controlled by this procedure. During this period, CCRT was performed in 82 patients with bladder cancer. This represents $41 \%$ of patients with bladder cancer, in whom radiotherapy was required, being treated with radiotherapy alone.

Staging investigations. Staging was performed using findings of contrast-enhanced computed tomography (CT), magnetic resonance imaging (MRI), and cystoscopy of bladder. In four patients, staging was performed on radiological examination and urine cytology only. Whole-body CT was performed to exclude distant metastases. Positron emission tomography (PET) was performed for only two patients. Staging, therapeutic effect and presence or absence of recurrence was determined by a radiologist, radiotherapist and urologist.

Radiation therapy. The treatment plan was performed with CT after urination. Scans were assessed in 5-mm sections at the lesion site and $10-\mathrm{mm}$ sections elsewhere. The gross tumour volume (GTV) is the volume of the area occupied by the tumour as measured on imaging and cystoscopy. The clinical target volume (CTV) was defined as whole-bladder and GTV $+0.5 \mathrm{~cm}$. The internal target volume (ITV) is the CTV plus the tumour margin for any organ movement. The ITV included a $2 \mathrm{~cm}$ 'set up' margin to establish the planning target volume (PTV). The radiation field was defined as PTV plus a 5-mm leaf margin. In the end, the radiation field was defined as the whole-bladder plus approximately $2-2.5 \mathrm{~cm}$. We included any lymph node located near the bladder but did not select small/whole-pelvis irradiation.

Using a 10-MV X-ray beam, multifield irradiation to more than four fields (all coplanar irradiation) was administered. Each beam was created using PTV along the path of the beam with a margin. Intensity-modulated radiotherapy (IMRT) was not used because our institution has no established policy for use of this treatment modality in patients with bladder cancer. In this study, we used only 3D-CRT and not IMRT. Image-guided radiotherapy was not performed.

The Clarkson algorithm was used to calculate the irradiation dose. The minimum and maximum doses according to the PTV were $95 \%$ and $107 \%$, respectively. The whole-bladder with a 2- to 2.5-cm margin was irradiated with fractions of 1.8-2 Gy, up to a total dose of 40-50 Gy. In 11 patients treated with radiotherapy, a concomitant boost to the GTV (with $1-1.5 \mathrm{~cm}$ margin) was administered during the last one or two weeks of treatment, up to a total dose of 54-60 Gy. Patients who received a total dose of $60 \mathrm{~Gy}$, with some receiving higher doses of radiation in the small bowel, were administered a local boost of $20 \mathrm{~Gy}$ after their lesions had been reduced by irradiation at $40 \mathrm{~Gy}$, as early as possible. The others in whom optimal small-bowel dose was possible were administered a local boost of $10 \mathrm{~Gy}$ after their lesions had been reduced by irradiation at $50 \mathrm{~Gy}$. All other patients received conventional radiotherapy administered in a single fraction per day. None of the patients was administered with accelerated hyperfractionated radiation therapy.

Oral chemotherapy. Even among patients with bladder cancer for whom standard chemotherapy was contraindicated, those with relatively good general condition and those who provided informed consent continued with UFT (tegafur and uracil) treatment after radiotherapy. There was no strict protocol for the duration of the UFT treatment and this treatment was continued for the purpose of achieving local control (LC) as long as adverse drug effects were manageable.

Evaluation of initial clinical response and toxicity on follow-up. Follow-up response was assessed within 4 weeks from the date of completion of treatment by routine urine examination and cytology. Cystoscopy and CT scan were performed within 3 months after treatment as an option. The recommended follow-up protocol at our institute includes investigations at 3-month intervals for the first six months and every six months, thereafter. However, the majority of our patients, who received radiotherapy with a palliative intent tended to change hospitals, were unable to visit our hospital. Therefore, we were unable to carry out strict follow-up for many patients. In these cases, information on the patients' conditions was obtained from their families telephonically.

A complete response (CR) was defined as the disappearance of all disease as observed on cystoscopy or CT and absence of cytological class IV or V and absence of macrohaematuria. Partial response (PR) was defined as a reduction in macrohaematuria or a reduction in tumour size on $\mathrm{CT}$. Progressive disease (PD) was defined as either an increase of macrohaematuria or CT views or worsening of cytological grade. Stable disease (SD) was defined when there was no change in macrohaematuria or CT findings or cytological grade. Responses were scored when the treatment was most effective. Local recurrence was defined as changes similar to those of PD. The date of recurrence was determined as the first day when the PD criterion was observed. Adverse events were defined according to the Common Terminology Criteria (CTC) for Adverse Events, version 4.0, with toxicity graded as mild (CTC Grade 1), moderate (CTC Grade 2), severe (CTC Grade 3) or life-threatening (CTC Grade 4) (29). 
Statistical analysis. OS after 3D-CRT was calculated based on the interval from the last day of treatment to the date of death or of the most recent follow-up as of May 2016 with Kaplan-Meier method. Data on patients who reached the end of the follow-up period without sustaining an event were censored. LC was calculated based on the interval from the first day of treatment until local relapse. Data on patients who died with no evidence of recurrence were censored. Univariate survival comparisons were performed using the log-rank test. The analysed prognostic factors for survival were age $(<80 v s . \geq 80)$, T-stage ( $\leq \mathrm{T} 2 v s . \geq \mathrm{T} 3)$, PS $(\leq 1 v s . \geq 2)$, radiation dose ( $\leq 50 v s .>50)$, concurrent UFT (yes $v s$. no) and tumour grade (G2 vs. G3). Independent variables that showed a statistically significant association on univariate analysis were included in multivariate analysis. $p<0.05$ indicated statistical significance. All calculations and survival displays were conducted using SPSS 15.0 J statistical software (SSPS Inc., Chicago, IL, USA).

Patients' consent. The present study was a retrospective analysis of data on diagnosis and treatment. Written informed consent was obtained from all patients for inclusion of their data in the study. Patients' records/information were anonymised and de-identified prior to analysis in this study. All procedures performed in the studies were in accordance with the ethical standards of the institutional and/or national research committee and with the 1964 Helsinki declaration and its later amendments or comparable ethical standards.

\section{Results}

Patients' and treatment characteristics. Baseline patients characteristics are listed in Table I. Fifteen patients were administered a total radiation dose of $50 \mathrm{~Gy}$. Two patients who were administered radiation doses delivered at 3 Gy per fraction with haemostatic intent, completed their treatment courses earlier based on their general condition. In contrast, 11 patients with good general condition, whose maximal value of small-bowel radiation tolerance was possible, received at least 54 Gy to the GTV. Four patients were diagnosed based on cytology alone and, therefore, the grade of bladder cancer was estimated to be G2. UFT treatment was continued after irradiation in 12 patients $(35 \%)$ whose prevention of disease progression was deemed necessary due to mild adverse effects. TUR-BT was followed by irradiation in the majority of patients (30 patients, 88\%). Furthermore, TUR-BT after irradiation was performed in three patients.

Patients' survival, response and tumour recurrence. The median duration of follow-up was 34 months (range=1-99). Thirteen patients died during follow-up. The cause of death was primary disease or related to the primary disease in nine patients, other cancers in two and unknown in two patients. The 1-year and 3-year OS rates were $51.4 \%$ and $34.3 \%$, respectively (Figure 1).

Data on survival and prognostic factors identified on univariate and multivariate analyses are listed in Table II. Improved OS was associated with $\mathrm{T}$-stage (hazard ratio
Table I. Baseline clinical characteristics of patients.

\begin{tabular}{|c|c|}
\hline Characteristics & Number \\
\hline Patients & 34 \\
\hline Age, median (range) & $83(65-97)$ \\
\hline$<80$ years & 14 \\
\hline$\geq 80$ years & 20 \\
\hline \multicolumn{2}{|l|}{ Gender } \\
\hline Male & 20 \\
\hline Female & 14 \\
\hline \multicolumn{2}{|l|}{ PS } \\
\hline 1 & 27 \\
\hline 2 & 7 \\
\hline \multicolumn{2}{|l|}{ Histology } \\
\hline urothelial carcinoma & 30 \\
\hline Unknown & 4 \\
\hline \multicolumn{2}{|l|}{ T-stage } \\
\hline $\mathrm{T} 1$ & 3 \\
\hline $\mathrm{T} 2$ & 13 \\
\hline $\mathrm{T} 3$ & 9 \\
\hline $\mathrm{T} 4$ & 9 \\
\hline \multicolumn{2}{|l|}{$\mathrm{N}$-stage } \\
\hline 0 & 31 \\
\hline 1 & 3 \\
\hline \multicolumn{2}{|l|}{ Tumour grade } \\
\hline 2 & 15 \\
\hline 3 & 15 \\
\hline unknown & 4 \\
\hline Dose (Gy), median (range) & $50(30-60)$ \\
\hline $30 \mathrm{~Gy}, 3 \mathrm{~Gy} / \mathrm{f}$ & 1 \\
\hline $40 \mathrm{~Gy}, 2 \mathrm{~Gy} / \mathrm{f}$ & 2 \\
\hline $42 \mathrm{~Gy}, 3 \mathrm{~Gy} / \mathrm{f}$ & 1 \\
\hline $44 \mathrm{~Gy} / \mathrm{f}, 2 \mathrm{~Gy} / \mathrm{f}$ & 1 \\
\hline $45 \mathrm{~Gy}, 1.8 \mathrm{~Gy} / \mathrm{f}$ & 3 \\
\hline $50 \mathrm{~Gy}, 2 \mathrm{~Gy} / \mathrm{f}$ & 15 \\
\hline $54(50+4) \mathrm{Gy}, 2 \mathrm{~Gy} / \mathrm{f}$ & 2 \\
\hline $56(50+6) \mathrm{Gy}, 2 \mathrm{~Gy} / \mathrm{f}$ & 4 \\
\hline $60(0+10) \mathrm{Gy}, 2 \mathrm{~Gy} / \mathrm{f}$ & 3 \\
\hline $60(40+20) \mathrm{Gy}, 2 \mathrm{~Gy} / \mathrm{f}$ & 2 \\
\hline \multicolumn{2}{|l|}{ TUR-Bt } \\
\hline Yes & 30 \\
\hline No & 4 \\
\hline \multicolumn{2}{|l|}{ UFT } \\
\hline Yes & 12 \\
\hline No & 22 \\
\hline
\end{tabular}

PS, Performance status; UFT, tegafur-uracil; TUR-Bt, transurethral resection of the bladder tumour; $\mathrm{f}$, fraction.

$(\mathrm{HR})=5.423 ; 95 \%$ confidence Interval $(\mathrm{CI})=1.125-26.149$; $p=0.035)$ ) and radiation dose $>50$ Gy $\mathrm{HR}=10.625 ; 95 \%$ $\mathrm{CI}=1.067-105.839 ; \quad p=0.044)$ ) on both univariate and multivariate analyses. CR and PR were recorded in eight patients $(23.5 \%)$, each. Five patients in CR and 2 patients in PR were diagnosed on cystoscopy. SD occurred in 14 patients $(41 \%)$; PD and the outcomes were unknown in two patients $(6 \%)$, each. The overall response rate was $47 \%$ and the 3-year LC rate was $58.8 \%$ (Figure 2). 


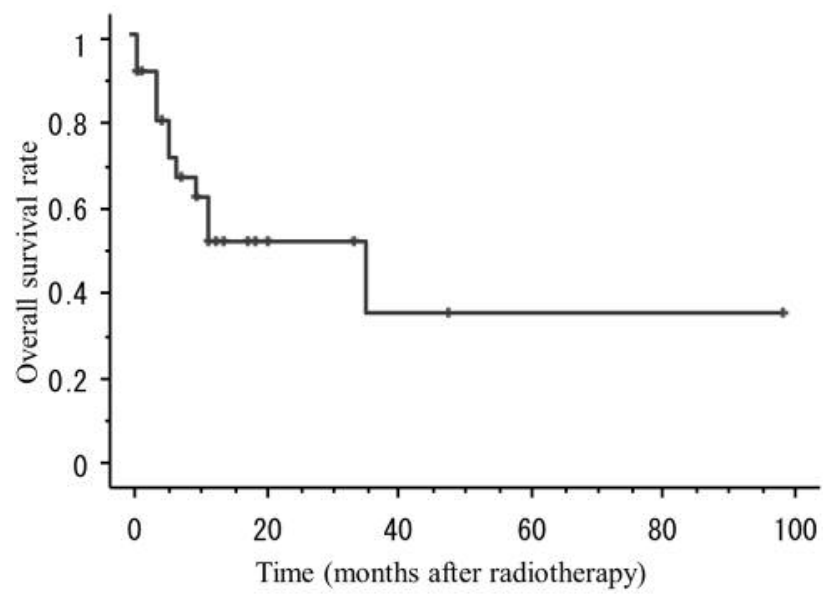

Figure 1. Overall survival in patients with bladder cancer treated with radiotherapy alone. The 1- and 3-year overall survival rates were 51.4 and $34.3 \%$, respectively.

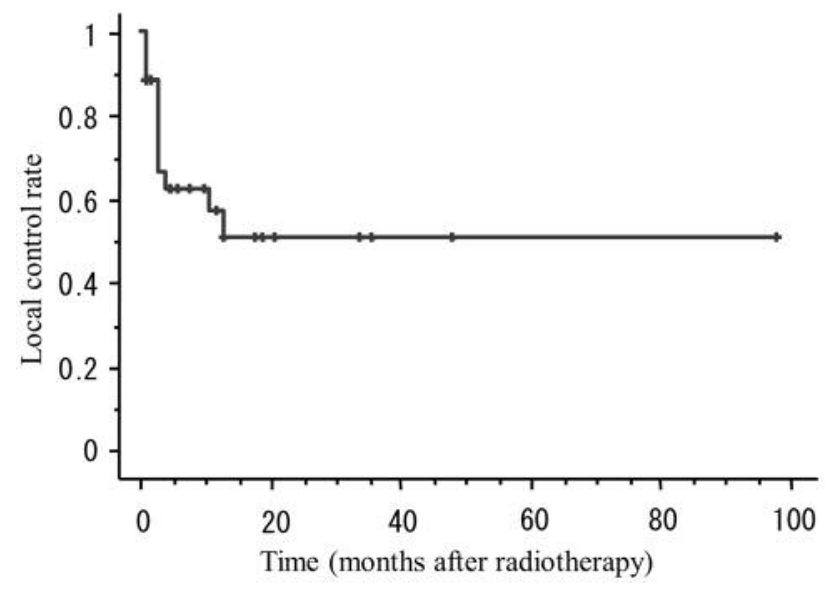

Figure 2. Patients had 3-year local control rate of $58.8 \%$.

On univariate analysis, radiation dose and UFT were significantly associated with LC (Table III). On multivariate analyses, only radiation dose was a significant predictor of LC $(\mathrm{HR}=11.784 ; 95 \% \mathrm{CI}=1.138-121.979 ; p=0.039)$.

Radiation toxicity. Acute genitourinary toxicity of Grade 1 and 2 was observed in 22/34 (65\%) and 2/34 (6\%) patients, respectively. Late gastrointestinal toxicity was not reported. No severe adverse events were observed.

\section{Discussion}

In this retrospective study, we investigated the possible role of 3D-CRT monotherapy for patients who refused and/or did
Table II. Correlates of overall survival on univariate and multivariate analysis.

\begin{tabular}{lcccc}
\hline Variables & $p$-Value & \multicolumn{3}{c}{ Multivariate analysis } \\
\cline { 3 - 5 } & & HR & $95 \%$ CI & $p$ \\
\hline $\begin{array}{l}\text { Age } \\
<80 ~ v s . \geq 80\end{array}$ & 0.161 & 1.140 & $0.239-5.435$ & 0.870 \\
PS & & & & \\
$\leq 1$ vs. $\geq 2$ & 0.201 & 0.192 & $0.028-1.304$ & 0.091 \\
T-stage & & & & \\
T1, 2 vs. T3, 4 & 0.011 & 5.423 & $1.125-26.149$ & 0.035 \\
Tumour grade & & & & \\
G2 or unknown vs. G3 & 0.346 & 0.500 & $0.101-2.469$ & 0.395 \\
$\begin{array}{l}\text { Dose } \\
\leq 50 \text { vs. }>50\end{array}$ & & & & \\
$\begin{array}{l}\text { UFT } \\
\text { Yes } v s . \text { no }\end{array}$ & 0.020 & 10.625 & $1.067-105.839$ & 0.044 \\
\hline
\end{tabular}

HR, Hazard ratio; CI, confidence interval; PS, performance status; UFT, tegafur-uracil.

Table III. Correlates of local control on univariate and multivariate analyses.

\begin{tabular}{lcccc}
\hline Variables & $p$-Value & \multicolumn{3}{c}{ Multivariate analysis } \\
\cline { 3 - 5 } & & HR & $95 \%$ CI & $p$ \\
\hline Age & & & & \\
$<80$ vs. $\geq 80$ & 0.542 & 0.356 & $0.084-1.509$ & 0.161 \\
PS & & & & \\
$\leq 1$ vs. $\geq 2$ & 0.337 & 0.663 & $0.120-3.647$ & 0.636 \\
T-stage & & & & \\
T1, 2 vs. T3, 4 & 0.125 & 2.396 & $0.588-9.769$ & 0.223 \\
$\begin{array}{l}\text { Tumour grade } \\
\text { G2 or unknown vs. G3 }\end{array}$ & 0.126 & 0.779 & $0.588-9.769$ & 0.745 \\
$\begin{array}{l}\text { Dose } \\
\leq 50 \text { vs. }>50\end{array}$ & & & & \\
UFT & 0.017 & 11.784 & $1.138-121.979$ & 0.039 \\
Yes $v s$. no & & & & \\
\hline
\end{tabular}

HR, Hazard ratio; CI, confidence interval; PS, performance status; UFT, tegafur-uracil.

not tolerate concurrent standard chemotherapy, based on CDDP for bladder cancer. TUR-BT was associated with a 3year OS of $34.3 \%$ with whole bladder or local radiotherapy. 
We found acute urinary toxicity rates of grade $\geq 2$ only in two patients, whereas none of the patients developed severe late urinary and intestinal toxicity. The main purpose of the present study was to establish the feasibility of radiotherapy alone in a cohort that is unfit for chemotherapy.

Regarding the usage of chemotherapy, RT with concurrent chemotherapy is a standard approach for bladder preservation. The key role of chemotherapy is to improve LC and reduce the likelihood of distant metastases. CCRT has been investigated in an attempt to take advantage of the radiosensitising capabilities of drugs in patients with invasive bladder cancers; concurrent chemotherapy has been wellrecognised to improve the clinical outcomes through improvement of the LC rates without compromising QOL (30, 31). Fluorouracil and mitomycin $\mathrm{C}$ are known to radiosensitize tumours but are not expected to have significant effects on systemic disease at the dose and schedule tested (11). In the present study, UFT, an oral prodrug of fluorouracil, was used based on the general condition of the patients. UFT is not a first-line treatment option for bladder cancer but is anticipated to increase radio-sensitization and improve LC of the disease. Our policy is that, although cisplatin-based chemotherapy is the standard treatment for bladder cancer, radiotherapy with or without UFT is selected as second-line treatment option for patients who are unable to receive first-line chemotherapy for various reasons.

In this study, we used 3D-CRT and not IMRT. Recent improvements in radiation therapy techniques have led to the widespread popularity of IMRT for reducing damage to normal tissues. However, IMRT requires greater precision and accuracy than 3D-CRT. Patients' characteristics, such as management of the urination and general physical condition, can render IMRT quite challenging to perform. Furthermore, IMRT is not available at all institutions and is used for bladder cancer only at a limited number of institutions. In such instances, it is reasonable to perform 3D-CRT. Thus, we believe that analysis of data on conventional 3D-CRT is of much clinical relevance.

The median age of patients in this study was 83 years, which is more than that in previous reports. Our results are comparable to those reported in previous studies $(11,32)$, especially with respect to the 3-year OS with radiotherapy alone (Figure 1). However, the 3-year OS with chemoradiotherapy alone reported by Maebayashi et al. (32) compares favourably to our results. This study reconfirmed radiotherapy alone to be inferior to CCRT, as previously reported. Given the older age of patients in our study, the results appear reasonable. The 3-year LC rate with radiotherapy alone $(58.8 \%)$ in the present study is comparable to that reported elsewhere $(53-64 \%)(23,26,27,33)$.

In the current study, radiotherapy was frequently performed for haemostatic purposes, as well as for lesion control. Owing to the older age of patients in our study, the incidence of complications was higher than that reported from other bladder cancer cohorts. However, symptom amelioration in these patients was comparable to that reported in previous studies.

On multivariate analyses, OS and LC were influenced significantly by the radiation dose $(\leq 50 \mathrm{vs}$. $>50)$. In the absence of concurrent chemotherapy, a tumour dose of $>50$ Gy (whole-bladder plus local boost) is advocated, except when small bowel dose constraints are exceeded. In our study, T-stage and radiation dose were a predictor of OS, whereas, in previous studies, tumour grade, tumour stage, performance status, complete resection and lymphatic invasion were all reported as predictors of OS $(16,28,33)$.

Previous studies have reported toxicity (grade $\geq 2$ ) rates of approximately $15 \%(23,28)$. In the present study, incidence of acute genitourinary toxicity of G2 was lower (6\%) than that reported earlier. Since the risk of bladder injury increases for doses $>50$ Gy (34), the tissue volume exposed to a boost dose of 55 Gy should be kept as small as possible. In the present study, because whole bladder plus local irradiation (not the entire bladder) was delivered if the total dose exceeded $50 \mathrm{~Gy}$, the incidence of adverse reactions may have been reduced.

In previous studies, the volume of bowel exposed to at least 45 Gy was most predictive of intestinal toxicity $(25,35)$. However, administration of a radiation dose of $50 \mathrm{~Gy}$ to the whole bladder inevitably exposes the small bowel as, in the majority of elderly patients, the small bowel often drops downward into the pelvis. The same was true for this study. The irradiated volume should be decreased whenever possible; however, the small bowel can necessarily be included in the irradiated field in elderly patients whose urine output is insufficient to prepare for radiation therapy and if the institution lacks the ability to perform intensity modulated radiation therapy and image-guided radiation therapy.

In this study, no serious adverse reactions occurred in patients receiving $50 \mathrm{~Gy}$ to the whole bladder with a 2- to $2.5-\mathrm{cm}$ margin, even if the small bowel was included in the irradiated field.

The relatively short follow-up duration and the small sample size are key limitations of our study because of which the results of multivariate analyses were unclear. Many of the patients studied received radiotherapy with palliative intent. Some were then transferred to other hospitals immediately after irradiation and others were lost to follow-up. Therefore, the LC rate was sometimes assessed based on the degree of haematuria as the CT and cystoscopy results could not be used as reference data. Thus, the assessment of the local control rate in some cases was not accurate. The acute toxicity rate was accurately assessed in our study, though the late toxicity rate could not be assessed due to the short duration of follow-up. These limitations may be addressed in the future studies. 


\section{Conclusion}

The retrospective nature of this study and the small sample size of patients who were available within a single centre do not detract from the value of these preliminary findings. This study demonstrated that 3D-CRT may be used as monotherapy for patients with bladder cancer, as a second-treatment option for patients who are unable to undergo operation/CCRT. Although the therapeutic efficacy outcomes in this small study were inferior to those reported for CCRT, the safety outcomes and the feasibility were comparable. Furthermore, we found that >50 Gy (50 Gy plus focal simultaneous boost) improved OS and LC without a significant increase in adverse events. These findings support a role for 3D-CRT alone as a treatment option for patients who refuse or may not tolerate CCRT, as well as for elderly patients with bladder cancer with a high chance of preservation of bladder function. The results of this study may represent reference information for radiotherapeutic management of bladder cancer.

\section{Conflicts of Interest}

The Authors declare no conflicts of interest and no financial disclosures.

\section{Acknowledgements}

None.

\section{References}

1 Matsuda A, Matsuda T, Shibata A, Katanoda K, Sobue T and Nishimoto H: Japan Cancer Surveillance Research Group. Cancer incidence and incidence rates in Japan in 2007: a study of 21 population-based cancer registries for the Monitoring of Cancer Incidence in Japan (MCIJ) Project. Jpn J Clin Oncol 43: 328-336, 2013.

2 Messing EM, Young TB, Hunt VB, Gilchrist KW, Newton MA, Bram LL, Hisgen WJ, Greenberg EB, Kuglitsch ME and Wegenke JD: Comparison of bladder cancer outcome in men undergoing hematuria home screening versus those with standard clinical presentations. Urology 45: 387-396, 1995.

3 Grossman HB, Natale RB, Tangen CM, Speights VO, Vogelzang NJ, Trump DL, deVere White RW, Sarosdy MF, Wood DP Jr, Raghavan D and Crawford ED: Neoadjuvant chemotherapy plus cystectomy compared with cystectomy alone for locally advanced bladder cancer. N Engl J Med 349: 859-866, 2003.

4 Stein JP, Lieskovsky G, Cote R, Groshen S, Feng AC, Boyd S, Skinner E, Bochner B, Thangathurai D, Mikhail M, Raghavan D and Skinner DG: Radical cystectomy in the treatment of invasive bladder cancer: Long-term results in 1,054 patients. J Clin Oncol 19: 666-675, 2001.

5 R.del C, Grabenbauer GG, Kühn R, Papadopoulos T, Dunst J, Meyer M, Schrott KM and Sauer R: Combined-modality treatment and selective organ preservation in invasive bladder cancer: Long-term results. J Clin Oncol 20: 3061-3071, 2002.
6 Shipley WU, Kaufman DS, Tester WJ, Pilepich MV and Sandler HM, Radiation Therapy Oncology Group: Overview of bladder cancer trials in the Radiation Therapy Oncology Group. Cancer 97: 2115-2119, 2003.

7 Khosravi-Shahi P and Cabezón-Gutiérrez L: Selective organ preservation in muscle-invasive bladder cancer: Review of the literature. Surg Oncol 21: e17-e22, 2012.

8 Hautmann RE, Gschwend JE, de Petriconi RC, Kron M and Volkmer BG: Cystectomy for transitional cell carcinoma of the bladder: Results of a surgery only series in the neobladder era. J Urol 176: 486-492, 2006.

9 Shariat SF, Karakiewicz PI, Palapattu GS, Lotan Y, Rogers CG, Amiel GE, Vazina A, Gupta A, Bastian PJ, Sagalowsky AI, Schoenberg MP and Lerner SP: Outcomes of radical cystectomy for transitional cell carcinoma of the bladder: A contemporary series from the Bladder Cancer Research Consortium. J Urol 176: 2414-2422, 2006.

10 Ghoneim MA, Abdel-Latif M, El-Mekresh M, Abol-Enein H, Mosbah A, Ashamallah A and el-Baz MA: Radical cystectomy for carcinoma of the bladder: 2,720 consecutive cases 5 years later. J Urol 180: 121-127, 2008.

11 James ND, Hussain S, Hall E, Jenkins P, Tremlett J, Rawlings C, Crundwell M, Sizer B, Sreenivasan T, Hendron C, Lewis R, Waters R and Huddart RA: Radiotherapy with or without chemotherapy in muscle-invasive bladder cancer. N Engl J Med 366: 1477-1488, 2012.

12 Witjes JA, Compérat E, Cowan NC, De Santis M, Gakis G, Lebret T, Ribal MJ, Van der Heijden AG and Sherif A: European Association of Urology. EAU guidelines on muscle-invasive and metastatic bladder cancer: Summary of the 2013 guidelines. Eur Urol 65: 778-792, 2014.

13 Lagrange J-L, Bascoul-Mollevi C, Geoffrois L, Beckendorf V, Ferrero J-M, Joly F, Allouache N, Bachaud JM, Chevreau C, Kramar A and Chauvet B, Study Group on Genito-Urinary Tumors: Quality of life assessment after concurrent chemoradiation for invasive bladder cancer: Results of a multicenter prospective study (GETUG 97-015). Int J Radiat Oncol Biol Phys 79: 172-178, 2011.

14 Hayter CR, Paszat LF, Groome PA, Schulze K, Math M and Mackillop WJ: A population-based study of the use and outcome of radical radiotherapy for invasive bladder cancer. Int J Radiat Oncol Biol Phys 45: 1239-1245, 1999.

15 Efstathiou J, Spiegel DY, Shipley WU, Heney NM, Kaufman DS, Niemierko A, Coen JJ, Skowronski RY, Paly JJ, McGovern FJ and Zietman AL: Long-term outcomes of selective bladder preservation by combined modality therapy for invasive bladder cancer: The MGH experience. Eur Urol 61: 705-711, 2012.

16 Munro NP, Sundaram SK, Weston PMT, Fairley L, Harrison SCW, Forman D and Chahal R: A 10-year retrospective review of a nonrandomized cohort of 458 patients undergoing radical radiotherapy or cystectomy in Yorkshire, UK. Int J Radiat Oncol Biol Phys 77: 119-124, 2010.

17 Arcangeli G, Strigari L and Arcangeli S: Radical cystectomy versus organ-sparing trimodality treatment in muscle-invasive bladder cancer: A systematic review of clinical trials. Crit Rev Oncol Hematol 95: 1-10, 2015.

18 Yadav BS, Ghoshal S and Sharma SC: Outcome following radical cystectomy and bladder-preservation therapy in patients with invasive carcinoma of urinary bladder. Indian J Urol 24: 48-53, 2008. 
19 Kaufman DS, Winter KA, Shipley WU, Heney NM, Wallace HJ 3rd, Toonkel LM, Zietman AL, Tanguay S and Sandler HM: Phase I-II RTOG study (99-06) of patients with muscle-invasive bladder cancer undergoing transurethral surgery, paclitaxel, cisplatin, and twice-daily radiotherapy followed by selective bladder preservation or radical cystectomy and adjuvant chemotherapy. Urology 73: 833-837, 2008.

20 Higano CS, Tangen CM, Sakr WA, Faulkner J, Rivkin SE, Meyers FJ, Hussain M, Baker LH, Russell KJ and Crawford ED, Southwest Oncology Group Trial 8733: Treatment options for muscle-invasive urothelial cancer for patients who were not eligible for cystectomy or neoadjuvant chemotherapy with methotrexate, vinblastine, doxorubicin, and cisplatin: Report of Southwest Oncology Group Trial 8733. Cancer 112: 2181-2187, 2008 .

21 Zapatero A, Martin De Vidales C, Arellano R, Ibañez Y, Bocardo G, Perez M, Rabadan M, García Vicente F, Cruz Conde JA and Olivier C: Long-term results of two prospective bladder-sparing trimodality approaches for invasive bladder cancer: neoadjuvant chemotherapy and concurrent radio-chemotherapy. Urology 80 : 1056-1062, 2012.

22 Krause FS, Walter B, Ott OJ, Häberle L, Weiss C, Rödel C, Wullich B and Sauer R: 15-year survival rates after transurethral resection and radiochemotherapy or radiation in bladder cancer treatment. Anticancer Res 31: 985-990, 2011.

23 Langsenlehner T, Döller C, Quehenberger F, Stranzl-Lawatsch $\mathrm{H}$, Langsenlehner U, Pummer K and Kapp KS: Treatment results of radiation therapy for muscle-invasive bladder cancer. Strahlentherapie und Onkol 186: 203-209, 2010.

24 Pos FJ, Van Tienhoven G, Hulshof MCCM, Koedooder K and González GD: Concomitant boost radiotherapy for muscle invasive bladder cancer. Radiother Oncol 68: 75-80, 2003.

25 Søndergaard J, Holmberg M, Jakobsen AR, Agerbæk M, Muren LP and Høyer M: A comparison of morbidity following conformal versus intensity-modulated radiotherapy for urinary bladder cancer. Acta Oncol 53: 1321-1328, 2014

26 Cowan RA, McBain CA, Ryder WDJ, Wylie JP, Logue JP, Turner SL, Van der Voet J, Collins CD, Khoo VS and Read GR: Radiotherapy for muscle-invasive carcinoma of the bladder: Results of a randomized trial comparing conventional whole bladder with dose-escalated partial bladder radiotherapy. Int J Radiat Oncol Biol Phys 59: 197-207, 2004.

27 Yavuz AA, Yavuz MN, Ozgur GK, Colak F, Ozyavuz R, Cimsitoglu E and Ilis E: Accelerated superfractionated radiotherapy with concomitant boost for invasive bladder cancer. Int J Radiat Oncol Biol Phys 56: 734-745, 2003.
28 Chahal R, Sundaram SK, Iddenden R, Forman DF, Weston PMT and Harrison SCW: A study of the morbidity, mortality and longterm survival following radical cystectomy and radical radiotherapy in the treatment of invasive bladder cancer in Yorkshire. Eur Urol 43: 246-257, 2003.

29 U.S. Department of Health and Human Services, National Institutes of Health, National Cancer Institute: Common Terminology Criteria for Adverse Events (CTCAE). Version 4.0. May 29th, 2009. http://evs.nci.nih.gov/ftp1/CTCAE/CTCAE_ 4.03_2010-06-14_QuickReference_8.5x11.pdf. Accessed 18th May 2015.

30 Chen WC, Liaw CC, Chuang CK, Chen MF, Chen CS, Lin PY, Chang PL, Chu SH, Wu CT and Hong JH: Concurrent cisplatin, 5-fluorouracil, leucovorin, and radiotherapy for invasive bladder cancer. Int J Radiat Oncol Biol Phys 56: 726-733, 2003.

31 Efstathiou JA, Bae K, Shipley WU, Kaufman DS, Hagan MP, Heney NM and Sandler HM: Late pelvic toxicity after bladdersparing therapy in patients with invasive bladder cancer: RTOG 89-03, 95-06, 97-06, 99-06. J Clin Oncol 27: 4055-4061, 2009.

32 Maebayashi T, Ishikawa H, Yorozu A, Yoshida D, Katoh H, Nemoto K, Ishihara S, Takemoto S, Ishibashi N, Tokumaru S, and Akimoto T, Working Subgroup of Urological Cancers in Japanese Radiation Oncology Study Group: Patterns of practice in the radiation therapy for bladder cancer: Survey of the Japanese Radiation Oncology Study Group (JROSG). Jpn J Clin Oncol 44: 1109-1115, 2014.

33 Kotwal S, Choudhury A, Johnston C, Paul AB, Whelan P and Kiltie AE: Similar treatment outcomes for radical cystectomy and radical radiotherapy in invasive bladder cancer treated at a United Kingdom specialist treatment center. Int J Radiat Oncol 70: 456-463, 2008

34 Marks LB, Carroll PR, Dugan TC and Anscher MS: The response of the urinary bladder, urethra, and ureter to radiation and chemotherapy. Int J Radiat Oncol Biol Phys 31: 1257-1280, 1995.

35 Kavanagh BD, Pan CC, Dawson LA, Das SK, Li XA, Ten Haken RK and Miften M: Radiation dose-volume effects in the stomach and small bowel. Int J Radiat Oncol Biol Phys 76: 101107, 2010.
Received August 25, 2016

Revised September 6, 2016 Accepted September 7, 2016 